\title{
INTESTINAL PARASITIC INFECTION IN SCHOOL GOING CHILDREN IN KATIHAR, BIHAR
}

\author{
Anamika Singh¹, Sangeeta Dey², Aninda Sen³, Dhanjay Kumar4, Kahkashan Akthar ${ }^{5}$ \\ 1 Final Year Postgraduate Student, Department of Microbiology, Katihar Medical College, Katihar. \\ 2 Professor and HOD, Department of Microbiology, Katihar Medical College, Katihar. \\ 3 Professor, Department of Microbiology, Katihar Medical College, Katihar. \\ ${ }_{4}^{4}$ Assistant Professor, Department of Microbiology, Katihar Medical College, Katihar. \\ ${ }^{5}$ Assistant Professor, Department of Microbiology, Katihar Medical College, Katihar.
}

\begin{tabular}{l}
\hline ABSTRACT \\
BACKGROUND \\
Intestinal parasitic diseases constitute a global health burden in numerous developing countries, mainly due to faecal \\
contamination of water and food and represents a major cause of morbidity and mortality in children. Intestinal parasitic \\
infections can be responsible for a wide range of clinical manifestations. \\
The study was conducted to ascertain the burden of intestinal parasitic infections in school going children in Katihar District of \\
Bihar and compare different microscopic techniques for detection of intestinal parasites.
\end{tabular}

\section{MATERIALS AND METHODS}

Faecal samples were examined for intestinal parasitic infections by direct microscopy and also after formol-ether concentration technique. Saline and iodine preparations were made and examined by light microscope. Smears were prepared and stained by modified Ziehl-Neelsen method and auramine 0 stain to look for acid fast oocysts.

Study Design- This is a cross-sectional prospective study conducted in Department of Microbiology, Katihar Medical College, Katihar, Bihar.

Statistical Analysis- Was done by Chi-square test to find the probability ratio using online software at http://www.physics.csbju.edu/stats/contingency

\section{RESULTS}

A total of 250 stool samples were collected from December 2015 to March 2017, out of which 95 samples did not show any parasites and 155 samples showed the presence of parasites. Parasites present were Ascaris lumbricoides 68 (27.2\%) followed by Entamoeba 38 (15.2\%), Giardia lamblia 29 (11.6\%), Taenia 23 (9.2\%), Hymenolepis nana 17 (6.8\%), Trichuris trichiura 10 (4\%), hookworm 7 (3.2\%), Strongyloides stercoralis 8 (3.2\%) and Enterobius vermicularis 4 (1.6\%). Oocyst of Cryptosporidium parvum was seen in $8(3.2 \%)$, Cystoisospora belli in $5(3.2 \%)$ and Cyclospora cayetanensis in $3(1.2 \%)$. Infection with more than one parasite was seen in $8.4 \%$ cases. Parasitic infection rates were found to be as high as $62 \%$ in school going children in our study, which comprised of children from semi-urban and rural areas.

\section{CONCLUSION}

Parasitic infection rates were found to be high, $62 \%$ of school going children in our study, which comprised of children from semiurban and rural areas were found to have parasitic infections. Ascaris lumbricoides was the commonest helminthic infection and entamoeba the commonest protozoal infection.

\section{KEYWORDS}

Parasitic Infections, School Going Children.

HOW TO CITE THIS ARTICLE: Singh A, Dey S, Sen A, et al. Intestinal parasitic infection in school going children in Katihar, Bihar. J. Evolution Med. Dent. Sci. 2018;7(05):637-640, DOI: 10.14260/jemds/2018/144

\section{BACKGROUND}

Intestinal parasitic disease constitutes a global health burden in numerous developing countries, mainly due to faecal contamination of water and food. More than 610 million children of school age are at risk of morbidity due to soiltransmitted helminthiasis. There are many negative effects of intestinal parasites in school children. Health problems such as malnutrition, anaemia, growth retardation, diarrhoea, vomiting/ nausea and intestinal obstruction are common in

'Financial or Other Competing Interest': None.

Submission 18-12-2017, Peer Review 13-01-2018,

Acceptance 20-01-2018, Published 29-01-2018.

Corresponding Author:

Dr. Sangeeta Dey,

Department of Microbiology,

Katihar Medical College, Katihar.

E-mail: sangeetadey@rediffmail.com

DOI: $10.14260 /$ jemds/2018/144

\section{(c) $($ ) $\$$}

children with parasitic infestation. The highest rates of infection are often seen in children in the age group from 5 to 15 years. $^{1}$

An estimated 1,471 million cases of infection with Ascaris lumbricoides, 1,200 million cases of infection with hookworm, 1,049 million cases of infection with Trichuris trichiura and 200 - 300 million cases of schistosomiasis have been reported worldwide. ${ }^{2}$ In Bihar it has been seen that malnutrition, unhygienic conditions, improper disposal of sewage, non-availability of portable water supply in rural and urban areas coupled with low literacy rates of parents, particularly the mothers are the main causes of these infections. ${ }^{3}$ In children, parasitic infestations either present as primary condition for which treatment is sought or incidentally detected when stool examination is done during health surveys or as routine when suffering from other disease. Asymptomatic cases pose a constant threat to the community by perpetuating the chain of transmission to 
others. ${ }^{4}$ These infestations in spite of their considerable morbidity are often ignored and considered neglected tropical diseases probably due to relatively low incidence of serious morbidity due to such infestations and the study of these diseases receives less than $1 \%$ of global research dollars. ${ }^{5}$ The Mass Drug Administration Program under National Filarial Control Program implementation is effectively decreasing the prevalence of soil transmitted helminthiasis, but there is need for proper diagnostic techniques to identify the existing and new cases in the community. The routinely done stool examination techniques for intestinal parasites are direct wet mount (saline and iodine mount) examination and stool concentration methods such as formalin-ether sedimentation and saturated salt flotation method. ${ }^{3}$ Formalin-ether sedimentation is the gold standard techniques for parasitic stool examination. It involves diethyl-ether as an essential agent which acts as a fat solvent to clear out the debris and increases the detection rate. This technique concentrates the parasitic eggs, cysts and larvae in the stool. Diethyl ether is highly inflammable and explosive, and its exposure may cause serious health hazards. If inhaled or absorbed through skin for long term, it may act as mutagen and may also cause neurotoxicity or carcinoma in some individuals. Other fat solvents such as ethyl acetate, tween, acetone and petrol have been proposed as alternatives. Among these chemicals acetone is a common, cheap and easily available laboratory chemical. It is more stable, non-toxic and non-carcinogenic. It increases detection rate of ova and cysts of intestinal parasites when used for stool concentration in conjunction with formalin. There is lack of comparative studies to substantiate its benefits and diagnostic efficacy over ether. ${ }^{3}$

The main objective of this study was to estimate the prevalence of intestinal parasitic infection in school going children of rural areas as compared to urban areas.

\section{MATERIALS AND METHODS}

This is a cross-sectional prospective study. Faecal samples were collected from school going children between 5 - 14 years of age from schools in Katihar, Bihar from December 2015 to May 2017 and subjected to microscopic examination, both before and after concentration of the samples. Institutional Ethical Committee clearance and informed consent was obtained from each patient before conducting the study.

\section{Specimen Collection}

Stool specimens from 250 school children with age ranging between 5 and 14 years were collected in a clean, dry, leakproof and sturdy wide mouth container. The samples were transported to the Microbiology Laboratory with minimum delay. On the first day of visit, the children were generally examined, and height and weight were noted down along with age and other demographic parameters. The children were handed over the containers and asked to bring the stool samples the following day. These samples were then collected and brought to the laboratory for further examination. In case of liquid specimens, microscopy was done directly from the fresh specimens. In case of semi-solid and formed stools, microscopic examination was done both before and after concentration by formol-ether concentration technique. ${ }^{6}$

\section{Macroscopic Examination}

The stool samples were examined macroscopically, and the following points were noted down; colour, consistency, presence of mucous, presence of blood, presence of parasites or parasitic elements.

\section{Microscopic Examination}

Saline and iodine wet mounts were prepared directly from the sample and also after concentration and were examined under low power (10x) and high power (40x) objectives of light microscope. The direct wet mount was examined for presence of mucous, pus cells, RBC, vegetable cells, starch granules, macrophages, trophozoites, cysts, ova, larvae and Charcot-Leyden crystals. The wet mounts made after concentration of the stool samples were examined for the presence of ova and cysts.

\section{Modified Ziehl-Neelsen (ZN) Staining}

Modified ZN staining (Kinyoun's modification of acid fast staining) was done on smears made from both fresh and concentrated samples following oocyst concentration technique. The slides were screened under low power (10x), high power (40x) and oil immersion (100x) objectives of light microscope for identification of the coccidian parasites like Cryptosporidium parvum, Cystoisospora belli and Cyclospora cayetanensis. ${ }^{7}$

\section{Auramine-0 Staining}

This technique was used for identification of Cryptosporidium sp., Cystoisospora belli and Cyclospora cayetanensis. In this, heat-fixed smears of direct and concentrated stool samples were stained with phenolic auramine stain and then decolourised with acid alcohol. Counter staining was done using potassium permanganate. The oocysts showed apple green fluorescence with blue excitation filter (wave length 450 - $490 \mathrm{~nm}$ ), under high power and oil immersion objectives of fluorescent microscope. ${ }^{7}$

Statistical analysis was done by chi-square test. All statistical analysis was carried out using online statistical software http://www.physics.csbju.edu/stats/contingency_NROW_NC OLUMN_form.html

\section{RESULTS}

A total of 250 samples were obtained from school going children and processed in the laboratory. 155 samples showed the presence of parasites and 95 samples showed no parasites. A total of 221 parasites were detected in the 250 samples that were collected. Out of these parasites that were detected, $59.3 \%$ were from males and $40.7 \%$ were from females. Ascaris lumbricoides was the commonest parasite $68(30.7 \%)$ detected followed by Entamoeba histolytica 38 (17.1\%), Giardia lamblia 29 (13.1\%) and taenia species 23 (10.4\%) (Table 1).

Maximum number of parasites were detected in the age group $>10-11$ years $40(25.8 \%)$ followed by $>13-14$ years $22(14.1 \%)$ and $>8-9$ years $17(10.9 \%)$. In children with parasitic infections, stool samples were found to be of semisolid and loose consistency in $40.6 \%$ and $45.1 \%$ of cases respectively, whereas solid stool was seen in only $14.1 \%$ of 
cases. This finding was found to be statistically highly significant, $\mathrm{p}=0.000$ (Table 2).

Direct macroscopic examination showed presence of blood and mucous in $12.8 \%$ and $20.8 \%$ of samples respectively. Parasites were detected in 143 (57.2\%) and 155 $(62.0 \%)$ stool samples by direct examination and following concentration respectively, Fig. 1.

Overall, parasitic infections were found to be very low in children with average and good hygienic standards. $100 \%$ of children with hookworm, Strongyloides stercoralis, Enterobius vermicularis, Cystoisospora belli, Cyclospora cayetanensis had poor hygienic standards. 95.6\% of children with Taenia, 95.5\% with Ascaris lumbricoides and 92.1\% with Entamoeba histolytica infections also had poor hygienic standards, Table 3.

Out of 250 samples Cryptosporidium parvum oocysts was positive in 8 samples, Cystoisospora belli oocyst in 5 samples and Cyclospora cayetanensis oocyst was seen in 3 samples. Parasitic detection rate was greater following Formol ether oocyst concentration technique followed by Auramine 0 staining for Cryptosporidium parvum and Cystoisospora belli. However, for Cyclospora cayetanensis concentration of stool was not beneficial, Table 4 .

\begin{tabular}{|c|c|c|c|}
\hline Parasite & Male (\%) & Female (\%) & Total \\
\hline $\begin{array}{c}\text { Entamoeba } \\
\text { histolytica }\end{array}$ & $25(19.0)$ & $13(14.4)$ & $38(17.1)$ \\
\hline Giardia lamblia & $20(15.2)$ & $09(10.0)$ & $29(13.1)$ \\
\hline $\begin{array}{c}\text { Ascaris } \\
\text { lumbricoides }\end{array}$ & $38(29.0)$ & $30(33.3)$ & $68(30.7)$ \\
\hline Taenia & $15(11.4)$ & $08(08.8)$ & $23(10.4)$ \\
\hline Hookworm & $06(04.5)$ & $02(02.2)$ & $08(03.6)$ \\
\hline Hymenolepis nana & $10(07.6)$ & $07(07.7)$ & $17(07.6)$ \\
\hline Trichuris trichiura & $04(03.0)$ & $06(06.6)$ & $10(04.5)$ \\
\hline Enterobius & $00(00.0)$ & $04(04.4)$ & $04(01.8)$ \\
\hline
\end{tabular}

\begin{tabular}{|c|c|c|c|}
\hline vermicularis & & & \\
\hline $\begin{array}{c}\text { Strongyloides } \\
\text { stercoralis }\end{array}$ & $04(03.0)$ & $04(04.4)$ & 08 (03.6) \\
\hline $\begin{array}{l}\text { Cryptosporidium } \\
\text { parvum }\end{array}$ & $04(03.0)$ & $04(04.4)$ & 08 (03.6) \\
\hline Isospora belli & $02(01.5)$ & $03(03.3)$ & $05(02.2)$ \\
\hline $\begin{array}{l}\text { Cyclospora } \\
\text { cayetanensis }\end{array}$ & $03(02.2)$ & $00(00.0)$ & 03 (01.3) \\
\hline Total & $131(100.0)$ & $90(100.0)$ & $221(100)$ \\
\hline \multicolumn{4}{|c|}{$\begin{array}{c}\text { Table 1. Parasites Detected in Stool Samples of school } \\
\text { going Children }\end{array}$} \\
\hline
\end{tabular}

\begin{tabular}{|c|c|c|c|}
\hline $\begin{array}{c}\text { Consistency } \\
\text { of Stool }\end{array}$ & $\begin{array}{c}\text { Parasite } \\
\text { Present (\%)* }\end{array}$ & $\begin{array}{c}\text { Parasite } \\
\text { Absent (\%)* }\end{array}$ & Total \\
\hline Solid & $22(14.1)$ & $63(66.3)$ & $85(34.0)$ \\
\hline Semi-Solid & $63(40.6)$ & $26(27.3)$ & $89(35.6)$ \\
\hline Loose & $70(45.1)$ & $06(06.3)$ & $76(30.4)$ \\
\hline Total & $155(100.0)$ & $95(100.0)$ & $250(100.0)$ \\
\hline Table 2. Correlation between occurrence of Parasitic \\
Infection and Consistency of Stool \\
\hline
\end{tabular}

*P value 0.000

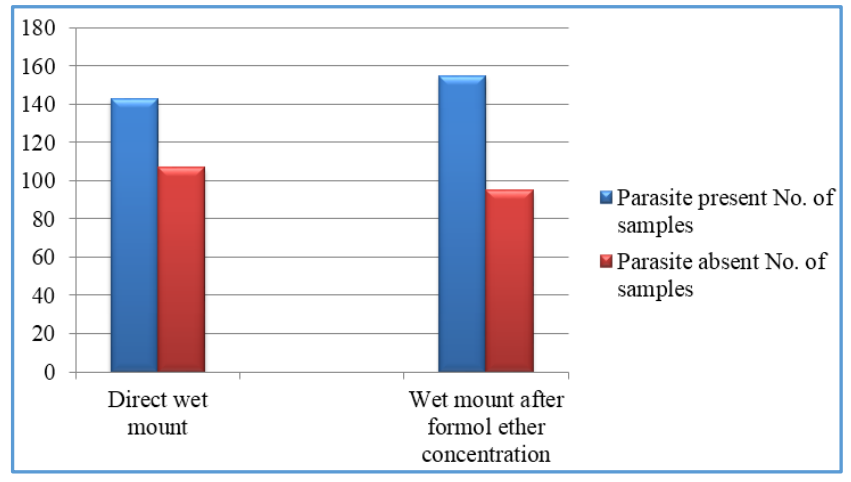

Figure 1. Samples showing Positive Findings on Microscope

\begin{tabular}{|c|c|c|c|c|c|c|c|c|c|c|}
\hline $\begin{array}{c}\text { Hygienic } \\
\text { Standard }\end{array}$ & EH & GL & AL & T & HN & TT & HW & SS & EV & CP \\
\hline Poor & 35 & 26 & 65 & 22 & 14 & 08 & 08 & 08 & 04 & 07 \\
$(92.1)$ & $(89.6)$ & $(95.5)$ & $(95.6)$ & $(82.3)$ & $(80.0)$ & $(100)$ & $(100)$ & $(100)$ & $(87.5)$ \\
\hline Average & 01 & 02 & 02 & 01 & 01 & 02 & 00 & 00 & 00 & 01 \\
$(2.6)$ & $(6.8)$ & $(2.9)$ & $(4.3)$ & $(5.8)$ & $(20.0)$ & $(0.0)$ & $(0.0)$ & $(0.0)$ & $(12.5)$ \\
\hline Good & 02 & 01 & 01 & 00 & 02 & 00 & 00 & 00 & 00 & 00 \\
$(0.4)$ & $(3.4)$ & $(1.4)$ & $(0.0)$ & $(11.7)$ & $(0.0)$ & $(0.0)$ & $(0.0)$ & $(0.0)$ & $(0.0)$ \\
\hline Total & 38 & 29 & 68 & 23 & 17 & 10 & 08 & 08 & 04 & 08 \\
\hline
\end{tabular}

EH- Entamoeba histolytica, GL- Giardia lamblia, AL- Ascaris lumbricoides, T- Taenia, HN- Hymenolepis nana, TT- Trichuris trichiura, HW- Hookworm, SS- Strongyloides stercoralis, EV- Enterobius vermicularis, CP- Cryptosporidium parvum.

\begin{tabular}{|c|c|c|c|}
\hline Microscopy & CP (\%) & CB (\%) & CC (\%) \\
\hline Direct ZN stain & $6(2.4)$ & $4(1.6)$ & $3(1.2)$ \\
\hline Direct Auramine O stain & $7(2.8)$ & $4(1.6)$ & $3(1.2)$ \\
\hline ZN stain after FEOC* & $7(2.8)$ & $4(1.6)$ & $3(1.2)$ \\
\hline Auramine O stain after FEOC & $8(3.2)$ & $5(2.0)$ & $3(1.2)$ \\
\hline \multicolumn{2}{|c|}{ Table 4. Oocysts Detected in Direct and Concentrated Stool Samples } \\
\hline
\end{tabular}

$\mathrm{n}=250,{ }^{*}$ FEOC- Formol-ether oocyst concentration, CP- Cryptosporidium parvum, CB- Cystoisospora belli, CC- Cyclospora cayetanensis.

\section{DISCUSSION}

Parasitic infections were found to be very high in the present study. $62 \%$ of school going children was found to be infected by one or more parasites. This could be due to the fact that majority of these children were from rural areas and had poor understanding of hygienic practices like proper hand washing before meals and after defecation. Parents of most of 
these children did not receive formal education or studied up to primary or middle school.

Ascaris was the commonest parasite detected followed by entamoeba and Giardia lamblia (Table 1). In a study involving school going children in Nepal, the authors reported Giardia lamblia in $44.3 \%$ of children, Entamoeba histolytica in $20.2 \%$, Ascaris lumbricoides in $4.3 \%$ and Taenia infection in $1.2 \%$ of children. They reported Cyclospora cayetanensis infection in 9.9\% of children. ${ }^{8}$ In the present study, Cyclospora cayetanensis was seen in only $1.3 \%$ of children.

Another study conducted in Nepal the following year found Giardia lamblia in $54.3 \%$ of children and Entamoeba histolytica in $19.6 \%$ of children. The variations seen in all these studies as far as detection rates of different parasites is concerned, is probably due to different geographical locations having prevalence of different parasites. ${ }^{9}$

In another study conducted in Egypt, Giardia lamblia was seen in $15.7 \%$ of children, which is similar to the findings of the present study. The same authors reported Cryptosporidium sp. in $11.7 \%$ and Hymenolepis nana in $2.3 \%{ }^{10}$ In the present study, Cryptosporidium sp. was seen in $3.6 \%$ of children and Hymenolepis nana in $7.6 \%$ of cases. ${ }^{10}$

In the present study, $31.5 \%$ children with positive findings were in the age group, i.e. 6 - 10 years. Similar findings were reported by other workers with maximum positivity in age group below 6 years $37.5 \%$ and $31.6 \%$ in the age group 6 - 10 years. ${ }^{9}$ Another study however found $81.3 \%$ positivity in the age group $>5$ years and $57.1 \%$ in the age group $6-10$ years, which is much higher as compared to the present study. ${ }^{11}$

Overall parasitic infections were found to be very low in children with average and good hygienic standards. All the children with hookworm, Strongyloides stercoralis, Enterobius vermicularis, Cystoisospora belli, Cyclospora cayetanensis and majority of children with taenia, ascaris and entamoeba infections had poor hygienic standards (Table 3). A significant correlation between hygienic practices and occurrence of parasitic infections have been found by others. ${ }^{8}$ Concentration of stool increased the detection of parasites, but not substantially (Fig, 1) as reported by other authors. ${ }^{11}$

The oocyst concentration technique followed by Auramine 0 staining was found to be beneficial only for detection of Cryptosporidium parvum and Cystoisospora belli, but only marginally. As the number of samples showing these parasites was very less, it is difficult to comment on the utility of this concentration technique.

\section{CONCLUSION}

Parasitic infection rates in school going children were found to be high in this part of the country. As observed in other parts of the country, Ascaris lumbricoides was the most common helminth detected. The number of taenia infection was found to be fairly high, probably due to high number of Muslim children in this group who consume beef and also a section of children in the rural areas who consume pork. Amongst the protozoan parasites detected, Entamoeba histolytica and Giardia lamblia were the most common. Cryptosporidium parvum, Cystoisospora belli and Cyclospora cayetanensis oocyst were also detected in a few cases where the children were apparently not immunocompromised. The formol ether and formol ether oocyst concentration though beneficial increased the percentage positivity to a small extent.
Parasitic infections even in present times appears to be a major public health problem, especially in school going children and more so in rural areas in India. This problem can be circumvented by simple means by doing microscopic examination of stool samples at periodic intervals and providing anti-helminthics at school level. Parasitic infections in children take a backstage as far as diseases of public health issues are concerned, due to the occurrence in this age group other diseases that lead to morbidity and mortality to a larger extent. Parasitic infections are by and large asymptomatic but decrease the quality of life in these children to a large extent by affecting proper growth and development as well as their ability to perform in school amongst other things like malnutrition, anaemia, diarrhoea and the risk of developing serious complications.

\section{REFERENCES}

[1] Dhanabal J, Selvadoss PP, Muthuswamy K. Comparative study of the prevalence of intestinal parasites in low socioeconomic areas from south Chennai, India. Journal of Parasitology Research Article ID: 630968, 2014;2014:1-7.

[2] Ezeamama AE, Friedman JF, Acosta LP, et al. Helminth infection and cognitive impairment among Filipino children. Am J Trop Med Hyg 2005;72(5):540-8.

[3] Ramakrishnan K, Kali A, Charles MVP, et al. Comparative evaluation of three stool concentration techniques in the diagnosis of intestinal parasitic infections. Int J Curr Microbiol App Sci 2016;5(11):299-304.

[4] Gabriel AS, Francisco JLA. World-wide importance of parasites. In: Topley $\&$ Wilsons parasitology. $10^{\text {th }}$ edn. Washington DC, Arnold E, Cox FEG, et al. (eds). 2005:24-46.

[5] Kulsum SN, Chadha T, Umar N. Study of incidence and spectrum of intestinal parasitic infestation using formalin ethyl acetate sedimentation technique among children and its correlation with anaemia. Biomedical \& Pharmacology Journal 2013;6(2):321-30.

[6] Cheesbrough M. Parasitological tests. In: District laboratory practice in tropical countries. $2^{\text {nd }}$ edn. New Delhi, Cambridge university press, 2012:198-9.

[7] Ahmed NH, Chowdhary A. Comparison of different methods of detection of enteric pathogenic protozoa. Indian J Med Microbiol 2013;31(2):154-60.

[8] Tandukar S, Ansari S, Shrestha A, et al. Intestinal parasitosis in school children of Lalitpur district of Nepal. BMC Res Notes 2013;6:449.

[9] Pradhan P, Bhandary S, Shakya PR, et al. Prevalence of intestinal parasitic infections among public school children in a rural village of Kathmandu Valley. Nepal Med Coll J 2014;16(1):50-3.

[10] Yones DA, Galal LA, Abdallah AM, et al. Effect of enteric parasitic infection on serum trace elements and nutritional status in upper Egyptian children. Trop Parasitol 2015;5(1):29-35.

[11] Amin HA, Ali SA. Evaluation of different techniques of stool examinations for intestinal parasitic infections in sulaimani city-Iraq. International Journal of Current Microbiology and Applied Sciences 2015;4(5):991-6. 